\title{
Solvothermal Preparation and Spectroscopic Characterization of Copper Indium Diselenide Nanorods
}

\author{
Yi-Han Yang and Yit-Tsong Chen* \\ Department of Chemistry, National Taiwan University, Taipei 106, Taiwan, and Institute of Atomic and \\ Molecular Sciences, Academia Sinica, P.O. Box 23-166, Taipei 106, Taiwan
}

Received: May 7, 2006; In Final Form: July 12, 2006

\begin{abstract}
Single-crystalline chalcopyrite $\mathrm{CuInSe}_{2}$ nanorods $\left(\mathrm{CuInSe}_{2} \mathrm{NRs}\right)$ of $50-100 \mathrm{~nm}$ in diameter and up to a few micrometers in length have been synthesized solvothermally. High-resolution transmission electron microscopic images of the $\mathrm{CuInSe}_{2} \mathrm{NRs}$ reveal the $d$-spacing of $0.335 \mathrm{~nm}$ for the (112) crystalline planes and a growth direction along [331]. The near-infrared absorption spectrum of the chalcopyrite $\mathrm{CuInSe}_{2} \mathrm{NRs}$ shows a peak maximum at $1162 \mathrm{~nm}$ and an onset at $1262 \mathrm{~nm}$, indicating no apparent blue-shift compared with those of $\mathrm{Cu}$-rich CuInSe $\mathrm{S}_{2}$ thin films. An intense peak at $175.1 \mathrm{~cm}^{-1}$ in the room-temperature Raman scattering spectrum of $\mathrm{CuInSe}_{2} \mathrm{NRs}$ corresponds to the $\mathrm{A}_{1}$ phonon mode of tetragonal CuInSe $\mathrm{C}_{2}$ chalcopyrite. The narrower full width at half-maximum (fwhm) of $9.5 \mathrm{~cm}^{-1}$ for $\mathrm{CuInSe}_{2} \mathrm{NRs}$, in comparison with fwhm $\sim 12 \mathrm{~cm}^{-1}$ for $\mathrm{CuInSe}_{2}$ films, indicates a uniform size distribution and single crystallization in the nanorods. Analysis of the photoluminescence from the single-crystalline $\mathrm{CuInSe}_{2} \mathrm{NRs}$ measured at $10 \mathrm{~K}$ has categorized the emission into seven groups of transitions as characterized by free excitons, bound excitons, conduction band to acceptor levels, and bound excitons at different defects.
\end{abstract}

\section{Introduction}

Because of the exhausting of fossil fuels, such as petroleum and coal, the development of new energy resources and their related environmental concerns has become an extremely important issue in recent years. Among many other potential energy sources, the renewable ones, such as photovoltaic electric generators, have drawn much attention. In particular, the use of the sun's radiant energy seems to be a sensible long-term goal. To make more efficient use of solar energy, a variety of solar cells have been developed for energy preservation.

The first solar cell was developed with the semiconductor material of single-crystalline silicon at Bell Laboratories by Chapin et al. more than a half century ago. ${ }^{1}$ The cell was applied as a power supply in space vehicles with a rough estimate for the energy conversion efficiency of $6 \%$. Because the cost of silicon was a significant proportion for the solar cell, a great deal of effort has been made to search for stable, highly conversion-efficient, and cost-effective substitutes. Ever since, laboratory demonstration cells of reduced minority-carrier recombination rate and trapping light in active layers have made dramatic increases in efficiency. For instance, fundamental GaAs solar cells ${ }^{2}$ and the double-junction laboratory cells of singlecrystalline $\mathrm{AlGaAs} / \mathrm{GaAs}^{3}$ and $\mathrm{GaInP}_{2} / \mathrm{GaAs}^{4}$ have reached 24, 27.6, and $29.5 \%$ conversion efficiencies, respectively.

As photovoltaic research extended beyond the simple elemental Si of Group IV to Group III-V compounds, such as GaAs, and then to Group II-VI compounds (e.g., CdTe), it has moved with one more step of complexity to $\mathrm{I}-\mathrm{III}-\mathrm{VI}_{2}$ compounds, such as copper indium diselenide $\left(\mathrm{CuInSe}_{2}\right)$. This $\mathrm{CuInSe}_{2}$ could be simplistically thought of as the result of substituting both Group I (Cu) and Group III (In) elements to give an average similar to the Group II element in II-VI

* Corresponding author. Phone: +886-2-2366-8238; fax: +886-2-23620200; e-mail: ytchen@pub.iams.sinica.edu.tw. crystals. Such a ternary compound represents the first step to more complicated solid solutions of more than three different atoms, with which both desired band gap and proper heterojunction lattice match could, in principle, be obtained to provide maximum efficiency. Research on quaternary and pentenary systems has also been under way; however, to date, these much more complex materials have not met the stringent demands of reproducibility and operating lifetime typically required for a solar-cell material. ${ }^{5}$

The ternary $\mathrm{I}-\mathrm{III}-\mathrm{VI}_{2}$ semiconductor of $\mathrm{CuInSe} \mathrm{S}_{2}$ has advantageous applications in thin-film solar cells because of its large absorption coefficient, low band gap $(\sim 1.05 \mathrm{eV})$, and good radiation stability. ${ }^{6-8}$ Films of $\mathrm{CuInSe}_{2}$ have been fabricated with various methods, such as molecular beam epitaxy, ${ }^{9}$ liquidphase epitaxy, ${ }^{10}$ and halogen vapor phase epitaxy. ${ }^{11}$ Polycrystalline $\mathrm{CuInSe} \mathrm{S}_{2}$ films have also been grown by metalorganic chemical vapor deposition using separate $\mathrm{Cu}$ and In precursors. ${ }^{12}$ To the best of our knowledge about the development of $\mathrm{CuInSe} \mathrm{S}_{2}$ nanostructures, there are only very few studies reported so far that include $\mathrm{CuInSe}$ nanoparticles $^{13}$ and $\mathrm{CuInSe} \mathrm{I}_{2}$ nanowhiskers. ${ }^{14}$ In this study, we report high-purity $\mathrm{CuInSe}_{2}$ nanorods (CuInSe $\mathrm{C}_{2} \mathrm{NRs}$ ) synthesized by a solvothermal method. $\mathrm{X}$-ray diffraction (XRD) and electron microscopic examinations of $\mathrm{CuInSe}_{2} \mathrm{NRs}$ have shown a single-crystalline structure for the chalcopyrite crystals. Spectroscopic characterizations for the $\mathrm{CuInSe}_{2} \mathrm{NRs}$ by near-infrared (NIR) absorption, micro-Raman scattering, and micro-photoluminescence (PL) spectroscopies will also be presented.

\section{Experimental Section}

The synthesis of $\mathrm{CuInSe}_{2} \mathrm{NRs}$ was conducted in a solvothermal reaction similar to the method by $\mathrm{Li}$ et al. ${ }^{14}$ In a typical experimental procedure, the product of $\mathrm{CuInSe}_{2}$ could be prepared from a stoichiometric mixture of Se powder (Strem, 
99.99\%), $\mathrm{In}_{2} \mathrm{Se}_{3}$ powder (Aldrich, $99 \%$ ), and $\mathrm{CuCl}_{2}$ anhydrous powder (Acros). The powder precursors were dissolved in ethylenediamine (Acros), which also acted as a reactant in this experiment, as will be discussed later. In the beginning of the solvothermal reaction, Se powder $(0.07896 \mathrm{~g})$ was added to 50 $\mathrm{mL}$ anhydrous ethylenediamine. The temperature was then increased to $\sim 120{ }^{\circ} \mathrm{C}$ by a heating plate. The solvothermal reaction was followed by the addition of both $\mathrm{In}_{2} \mathrm{Se}_{3}(0.46652$ g) and anhydrous $\mathrm{CuCl}_{2}(0.26890 \mathrm{~g})$ powders. The reaction temperature was kept at $\sim 120{ }^{\circ} \mathrm{C}$ throughout the reflux experiment. After the reaction, precipitates were filtered and washed several times with distilled water and ethanol to remove byproducts. The reaction product was dried at $60{ }^{\circ} \mathrm{C}$ for $6 \mathrm{~h}$ and used afterward for powder XRD analysis, electron microscopic measurements, and NIR, Raman, and PL spectroscopic characterizations.

The experimental details for the electron microscopic and spectroscopic characterizations of the as-synthesized CuInSe ${ }_{2} \mathrm{NRs}$ are similar to those of several previous studies in this laboratory, including $\mathrm{Si}$ nanowires, ${ }^{15} \mathrm{CdSe}$ nanobelts and nanosheets, ${ }^{16}$ $\mathrm{Zn}_{x} \mathrm{Cd}_{1-x}$ Se alloy nanowires, ${ }^{17}$ and $\mathrm{SiO}_{2}$ nanoparticles. ${ }^{18}$ Briefly, scanning electron microscopic (SEM) morphologies of the $\mathrm{CuInSe}_{2} \mathrm{NRs}$ were taken in a LEO 1530 field emission gun SEM and energy dispersive spectrometer (FEG-SEM+EDS). Transmission electron microscopic (TEM) images were obtained in a JEOL JEM-1200EX II TEM at $80 \mathrm{kV}$ and a Hitachi H-7100 TEM at $75 \mathrm{kV}$. High-resolution transmission electron microscopic (HRTEM) measurements were conducted in a JEOL JEM-2010 analytical TEM at $200 \mathrm{kV}$ and a JEOL JEM-4000EX HRTEM at $400 \mathrm{kV}$.

Spectroscopic examination of NIR absorption was performed in a Jasco V-570 UV/Vis/NIR spectrophotometer with a scanning range from 1100 to $1400 \mathrm{~nm}$. In the NIR spectroscopic investigation, the sample of $\mathrm{CuInSe}_{2} \mathrm{NRs}$ was suspended in ethylenediamine where ethylenediamine served as a background for reference. Micro-Raman spectra of $\mathrm{CuInSe}_{2} \mathrm{NRs}$ were recorded with the signal-accumulation time of $180 \mathrm{~s}$ in a confocal microscope (Jobin Yvon, MFO) combined with a system of a monochromator (Jobin Yvon, Triax 550) and a liquid-nitrogen-cooled charge-coupled device camera (Jobin Yvon, $1024 \times 256$ pixels). The 488-nm line of an $\mathrm{Ar}^{+}-\mathrm{Kr}^{+}$ laser (Coherent, Innova 70C) was used for the Raman excitation with a power level of $50 \mathrm{~mW}$. Crystal structures of the $\mathrm{CuInSe}_{2} \mathrm{NRs}$ were analyzed using an X-ray diffractometer (Philips, PNAalytical X'Pert PRO) of $\mathrm{Cu} \mathrm{K} \alpha$ radiation with a scanning range of $2 \theta$ from 20 to $70^{\circ}$. PL from the $\mathrm{CuInSe}{ }_{2} \mathrm{NRs}$, excited at $760 \mathrm{~nm}$ by an $\mathrm{AlGaAs}$ solid-state laser of $25 \mathrm{~mW}$, was collected by a double-grating monochromator (Jobin Yvon, Spex 1403) together with a liquid-nitrogen-cooled germanium detector (North Coast, EO807). The PL measurement was also conducted in the temperature range of $8-300 \mathrm{~K}$ with a closedcycle helium-cooled refrigerator (Edinburgh Instruments, STL20).

\section{Results and Discussion}

XRD of $\mathrm{CuInSe}_{2}$ NRs. To determine the crystal structures of the as-synthesized $\mathrm{CuInSe}_{2} \mathrm{NRs}$, the XRD pattern was examined as shown in Figure 1a. Seven prominent XRD peaks were identified as being due to the $\mathrm{CuInSe}_{2}$ crystal planes of (112), (211), (220), (204), (301), (312), and (400), which give a chalcopyrite tetragonal structure with lattice constants of $a=$ $0.5949 \mathrm{~nm}$ and $c=1.1443 \mathrm{~nm}$, consistent with the standard values of the reported $\mathrm{CuInSe}_{2}$ data (JCPDS No. 23-0209). Six XRD signals of much weaker intensities, which could not be assigned to chalcopyrite $\mathrm{CuInSe}_{2}$, were attributed to the Se-

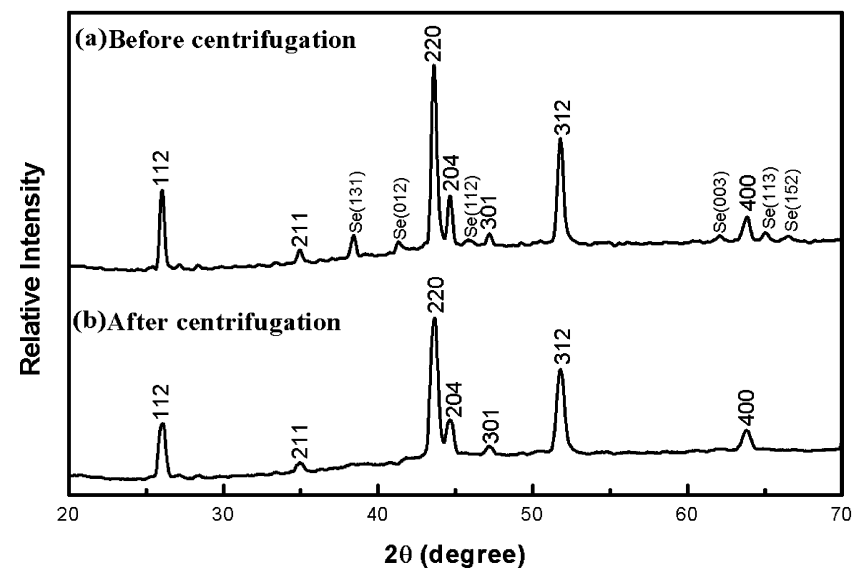

Figure 1. Labeled XRD spectra for the solvothermal products (a) before and (b) after high-speed centrifugation. Before centrifugation, both $\mathrm{CuInSe} \mathrm{S}_{2}$ chalcopyrite and Se-related nanocrystals are responsible for the observed XRD signals. After centrifugation, the Se nanocrystals have been removed effectively.

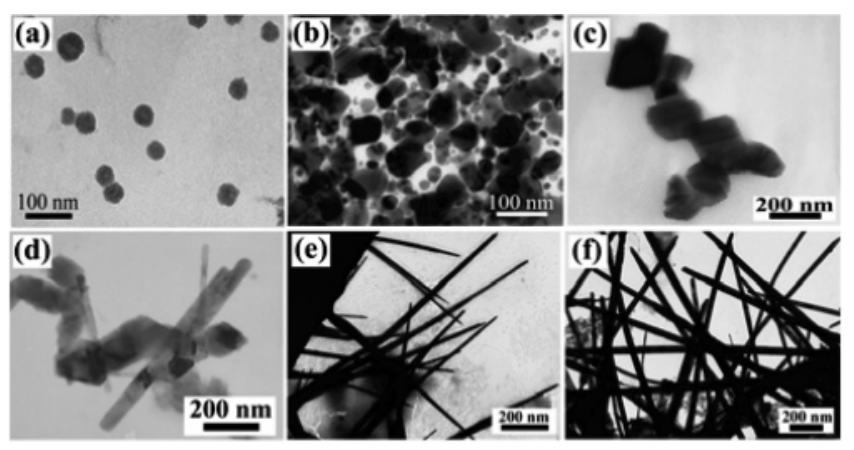

Figure 2. TEM morphologies for the CuInSe $\mathrm{C}_{2}$ nanocrystals in a series of solvothermal reactions with reflux times of (a) 12 , (b) 24 , (c) 28 , (d) 32, (e) 36, and (f) $48 \mathrm{~h}$. The morphologies of the as-synthesized $\mathrm{CuInSe}_{2}$ products evolving from nanoparticles to nanorods during the experimental course are manifested in panels a-f.

related structures of (131), (012), (112), (003), (113), and (152). This XRD result indicates a mixture of $\mathrm{CuInSe}_{2}$ and Se crystals in the product. To extract the $\mathrm{CuInSe}_{2} \mathrm{NRs}$ out of the mixture, we carried out a physical separation in a high-speed centrifuge (typically $\sim 10000 \mathrm{rpm}$ ). Figure $1 \mathrm{~b}$ shows the XRD pattern of tetragonal $\mathrm{CuInSe}_{2}$ crystallites after the high-speed centrifugation, indicating an effective separation.

Electron Microscopic Characterizations of $\mathrm{CuInSe}_{2} \mathrm{NRs}$. Figure $2 \mathrm{a}-\mathrm{f}$ presents the TEM images of six samples produced in the solvothermal reaction after a series of reflux times of 12, $24,28,32,36$, and $48 \mathrm{~h}$, respectively. With a relatively shorter reaction time ( $12 \mathrm{~h}$, Figure $2 \mathrm{a}$ ), the product is mainly spherical nanoparticles. In a longer experimental course, these nanoparticles were recrystallized to develop new morphologies, as shown in Figure 2 b. These irregularly shaped nanoparticles with a diameter range of $20-80 \mathrm{~nm}$ played an important role as initiators (or "seeds") for the growth of one-dimensional $\mathrm{CuInSe}_{2} \mathrm{NRs}$. Figure $2 \mathrm{c}$ shows the start of elongation of the nanoparticles to develop to nanorods at the reflux time of $28 \mathrm{~h}$. In the subsequent reaction period of $32 \mathrm{~h}$ of reflux (Figure $2 \mathrm{~d}$ ), some of the nanorods already possessed quite large aspect ratios and had grown to hundreds of nanometers in length. When the reaction time reached at least $36 \mathrm{~h}, \mathrm{CuInSe}{ }_{2} \mathrm{NRs}$ were found in the ethylenediamine solution with a high production yield. Shown in Figure 2e are the CuInSe ${ }_{2} \mathrm{NRs}_{50}-100 \mathrm{~nm}$ in diameter and up to a few micrometers in length. A TEM image of the as-synthesized $\mathrm{CuInSe}{ }_{2} \mathrm{NRs}$ after $48 \mathrm{~h}$ of reaction is presented 

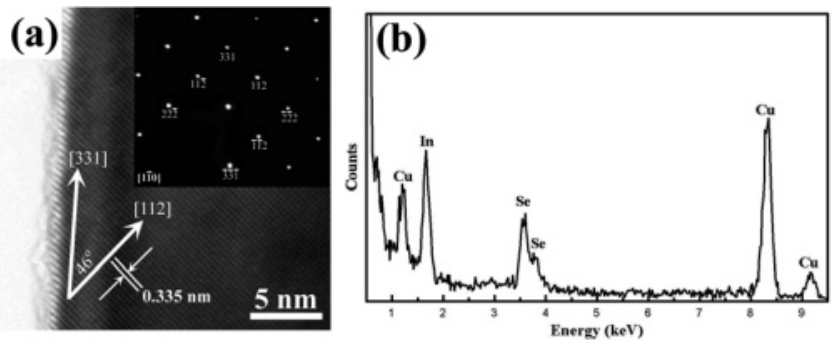

Figure 3. (a) HRTEM image of the $\mathrm{CuInSe}_{2} \mathrm{NRs}$. The $d$-spacing of $0.335 \mathrm{~nm}$ in the (112) planes and a growth direction along [331] have been identified on the basis of the SAED pattern (inset) with the [110] zone axis. (b) EDS analysis for the CuInSe ${ }_{2} \mathrm{NRs}$ indicates the molar ratio of $\mathrm{Cu} / \mathrm{In} / \mathrm{Se}=0.98: 0.87: 1.95$.

in Figure 2f, in which the morphology of $\mathrm{CuInSe}{ }_{2} \mathrm{NRs}$ is almost the same as that in Figure 2e, except more nanorods having been produced.

An HRTEM image of the $\mathrm{CuInSe} \mathrm{N}_{2} \mathrm{NRs}$ (Figure 3a) reveals their single-crystalline structure of $0.335 \mathrm{~nm} d$-spacing due to the (112) crystal planes. The growth direction of $\mathrm{CuInSe}_{2} \mathrm{NRs}$ along [331] has been analyzed from the selected-area electron diffraction (SAED) pattern, as shown in the inset of Figure 3a, with a zone axis of [1 10$]$. The angle between the rod-axial growth direction of [331] and the $<112>$ lattice growth direction is determined to be $\sim 46^{\circ}$. An EDS analysis (Figure $3 b)$ for the chemical compositions of $\mathrm{CuInSe}_{2} \mathrm{NRs}$ further confirms the stoichiometric ratio of $\mathrm{Cu} / \mathrm{In} / \mathrm{Se} \approx 1: 1: 2$ (strictly, 0.98:0.87:1.95).

Growth Mechanism for CuInSe $\mathrm{CRR}_{2}$. At room temperature, elemental Se is soluble in ethylenediamine. This dissolution is accompanied not only by a color change of the solution from opaque to brown, but also the instant disappearance of the Se powder. The increasing reactivity of Se is enhanced by its dispersion into ethylenediamine. In the solvothermal reaction, dissolved elemental Se was reduced to negatively charged $\mathrm{Se}^{2-}$ by amines in an organic nucleophilic attack, similar to how elemental $\mathrm{S}$ can be activated by amines or hydroxides. ${ }^{19}$ When temperature increased, the $\mathrm{In}_{2} \mathrm{Se}_{3}$ reactant, which has low solubility in ethylenediamine, reacted with the $\mathrm{Se}^{2-}$ ions to form $\mathrm{InSe}_{2}{ }^{-}$(eq 1 in the following summary reactions). According to previous studies on the fabrication of nanomaterials, ethylenediamine can facilitate the growth of one-dimensional nanostructures, ${ }^{20,21}$ in which the strong chelation ability of alkylamine is essential for the formation of chelated compounds as a template to build up one-dimensional structures. In this work, $\mathrm{Cu}^{2+}$ from $\mathrm{CuCl}_{2}$ was first reduced to $\mathrm{Cu}^{+}$as discussed previously by $\mathrm{Li}$ et al., ${ }^{14}$ which was then chelated by bidentate ethylenediamine (denoted by "en" in the following eq 2) to form the complex of $\left[\mathrm{Cu}(\mathrm{en})_{2}\right]^{+}$. According to the proposed structure of $\left[\mathrm{Cu}(\mathrm{en})_{2}\right]^{+}$ by $\mathrm{Li}$ et al., ${ }^{14}$ the ethylenediamine binds strongly with $\mathrm{Cu}^{+}$to form a two five-membered-ring chelated structure in which the $\mathrm{Cu}^{+}$bridges the amino groups of the two ethylenediamine moieties. In a recent theoretical study by Alcamí et al., ${ }^{22}$ the five-membered-ring structure, composed of $\mathrm{Cu}^{+}$and ethylenediamine, has further been calculated to be most stable in energy among possible isomeric structures. As mentioned by Li et al., ${ }^{14}$ $\mathrm{InSe}_{2}{ }^{-}$in ethylenediamine was self-organized with the $\left[\mathrm{Cu}(\mathrm{en})_{2}\right]^{+}$ complex to start nucleation and crystalline growth to generate the one-dimensional $\mathrm{CuInSe}_{2}$ nanostructures. The $\left[\mathrm{Cu}(\mathrm{en})_{2}\right]^{+}$ complex was also regarded as serving as a molecular template to guide the growth of $\mathrm{CuInSe}_{2} \mathrm{NRs}$ (eq 3), similar to that reported by Morris et al. ${ }^{23}$ on the study of a template growth mechanism. The proposed mechanism involved in this solvothermal reaction for the growth of $\mathrm{CuInSe}_{2} \mathrm{NRs}$ can be sum-

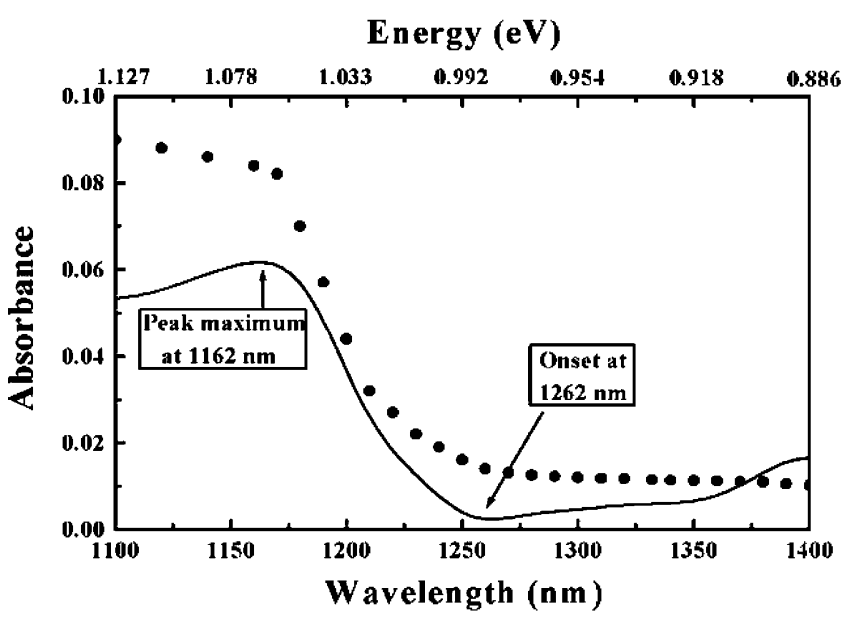

Figure 4. NIR absorption spectrum of the as-synthesized $\mathrm{CuInSe}_{2} \mathrm{NRs}$ with a peak maximum at $\sim 1162 \mathrm{~nm}$ and an onset at $\sim 1262 \mathrm{~nm}$. The dotted curve represents the absorption coefficient of $\mathrm{Cu}$-rich $\mathrm{CuInSe} \mathrm{I}_{2}$ proceeded films taken from refs 25 and 26.

marized in the following eqs $1-3$ :

$$
\begin{gathered}
\mathrm{In}_{2} \mathrm{Se}_{3}+\mathrm{Se}^{2-} \rightarrow 2 \mathrm{InSe}_{2}{ }^{-} \\
\mathrm{Cu}^{+}+2 \mathrm{en} \rightarrow\left[\mathrm{Cu}(\mathrm{en})_{2}\right]^{+} \\
\mathrm{InSe}_{2}{ }^{-}+\left[\mathrm{Cu}(\mathrm{en})_{2}\right]^{+} \rightarrow \mathrm{CuInSe}_{2}+2 \mathrm{en}
\end{gathered}
$$

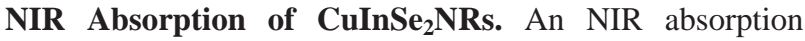
spectrum of the $\mathrm{CuInSe} \mathrm{IRs}_{2} \mathrm{NR}$ allustrated in Figure 4 was recorded from 1100 to $1400 \mathrm{~nm}$, with $\mathrm{CuInSe}_{2} \mathrm{NRs}$ being dispersed in ethylenediamine solution. Shown in Figure 4 are a peak maximum at $\sim 1162 \mathrm{~nm}$ and an onset at $\sim 1262 \mathrm{~nm}$, whose separation can be regarded as a guideline to evaluate the size distribution of the as-prepared semiconductor nanocrystallites. ${ }^{24}$ In comparison with the absorption spectrum, the dotted curve in Figure 4 of $\mathrm{Cu}$-rich $\mathrm{CuInSe} \mathrm{Se}_{2}$ proceeded films (sample $\mathrm{C}$ in ref 25 synthesized by Mooney et al.) observed by Kavcar, ${ }^{26}$ there is no apparent blue-shift (i.e., quantum confinement effect) in the absorption spectrum of $\mathrm{CuInSe}_{2} \mathrm{NRs}$. It is noted that the reported Bohr radius of $1.2 \mathrm{~nm}^{27}$ or $2.02 \mathrm{~nm}^{13}$ for the CuInSe compound is much smaller than the radii (typically $25-50 \mathrm{~nm}$ ) of the as-synthesized chalcopyrite $\mathrm{CuInSe}_{2} \mathrm{NRs}$, and a quantum confinement effect is unlikely to be observed in the present experiment.

Raman Scattering of $\mathrm{CuInSe}_{2}$ NRs. Figure 5 shows the room-temperature Raman scattering spectrum of $\mathrm{CuInSe}{ }_{2} \mathrm{NRs}$. The very strong signal at $175.1 \mathrm{~cm}^{-1}$ corresponds to the $\mathrm{A}_{1}$ optical phonon mode in tetragonal $\mathrm{CuInSe}_{2}$ crystal, consistent with the vibrational observation of $\mathrm{CuInSe} \mathrm{S}_{2}$ films where the $\mathrm{A}_{1}$ mode is much stronger than any other phonon mode. This $A_{1}$ mode relates to the vibration of two pairs of anions, one in the direction of the $a$-axis and the other in the direction of the $b$-axis. ${ }^{28}$ An analysis of the line widths further indicates that the full width at half-maximum (fwhm) of $\sim 9.3 \mathrm{~cm}^{-1}$ for $\mathrm{CuInSe}_{2} \mathrm{NRs}$ is narrower than the typical fwhm of $\sim 12-13$ $\mathrm{cm}^{-1}$ for $\mathrm{CuInSe} \mathrm{H}_{2}$ thin films, ${ }^{29}$ which could be attributed to more uniformity in size-distribution and better crystallization in the single-crystalline $\mathrm{CuInSe}{ }_{2} \mathrm{NRs}$.

Photoluminescence of $\mathrm{CuInSe}_{2} \mathbf{N R s}$. The PL spectrum (Figure 6) of the as-synthesized single-crystal $\mathrm{CuInSe}_{2} \mathrm{NRs}$, freely dispersed on a copper substrate, was obtained at $10 \mathrm{~K}$ with an excitation at $760 \mathrm{~nm}$ by a $25 \mathrm{~mW}$ solid-state laser. The well-resolved spectral features in Figure 6 are categorized into 


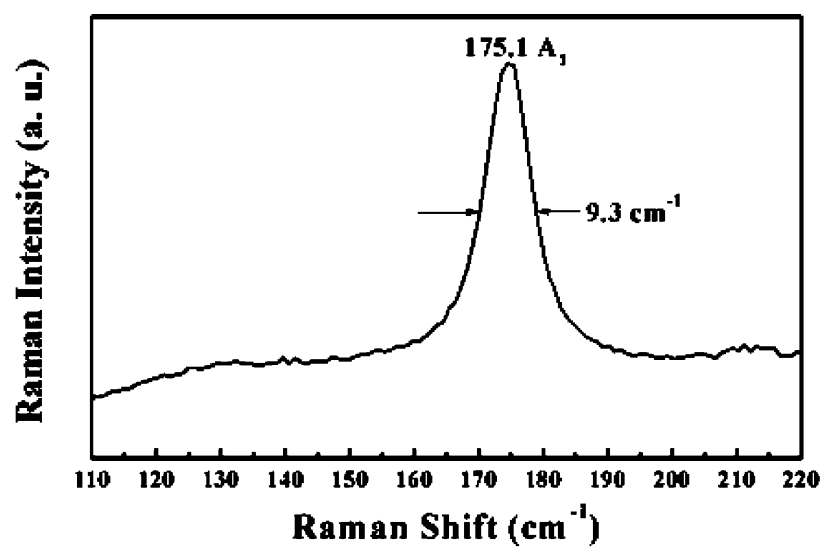

Figure 5. Raman-scattering spectrum of the $\mathrm{CuInSe}_{2} \mathrm{NRs}$. An intense $A_{1}$ phonon mode at $175.1 \mathrm{~cm}^{-1}\left(\mathrm{fwhm}=9.3 \mathrm{~cm}^{-1}\right)$ is observed with laser excitation at $488 \mathrm{~nm}$.

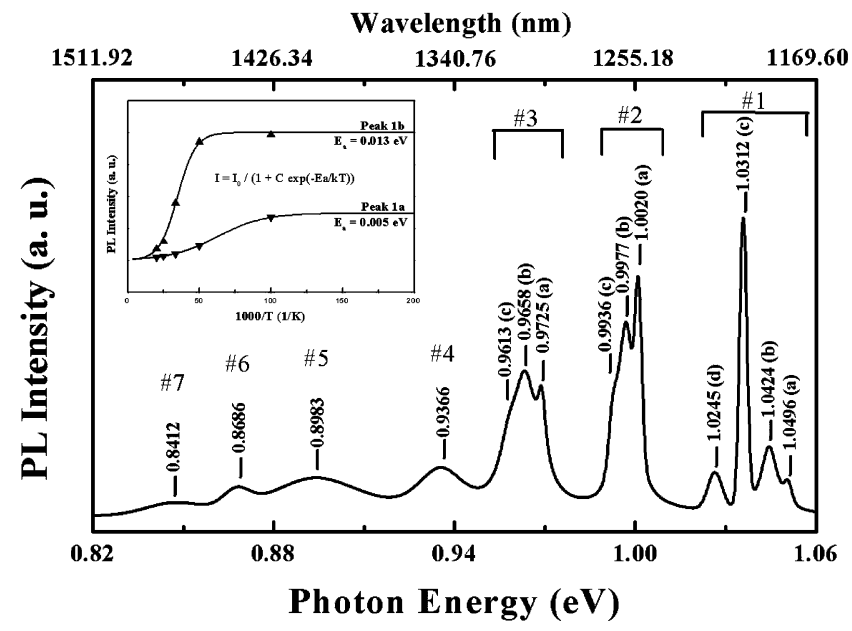

Figure 6. PL of the $\mathrm{CuInSe}_{2} \mathrm{NRs}$ at $10 \mathrm{~K}$ with laser excitation at 760 $\mathrm{nm}$. Inset shows the fitted activation/binding energies $\left(E_{\mathrm{a}}\right)$ for peaks $\# 1 \mathrm{a}$ and \#1b.

seven groups denoted \#1-\#7. The fine features in \#1-\#3 are further labeled by a, b, c, and d.

A CuInSe ${ }_{2}$ semiconductor has a direct band gap of $\sim 1.05$ $\mathrm{eV}$ at low temperature. It has been found that the tetragonal degeneracy in the valence-band maximum is lifted under both crystal-field and spin-orbital interactions. The splitting results in two closely spaced levels (with a separation of only a few millielectronvolts) and another one lying 233 meV below. ${ }^{30,31}$ The \#1 group, composed of one prominent and three weak features in Figure 6, is related to the transitions of bound excitons and free excitons. Yakushev et al. ${ }^{32,33}$ studied the PL spectra of single-crystal $\mathrm{CuInSe}_{2}$ at different temperatures and found that the intensities of both \#1a (1.0496 eV) and \#1b $(1.0424 \mathrm{eV})$ decrease slowly with increasing temperature; in contrast, those of \#1c $(1.0312 \mathrm{eV})$ and \#1d (1.0245 eV) decrease rapidly. On the basis of these results, while \#1a and \#1b are assigned to free-exciton transitions, \#1c and \#1d are due to bound-exciton transitions. To determine the energy band gap for the \#1a and \#1b transitions, the PL intensities of these two transitions were examined from 10 to $50 \mathrm{~K}$ as illustrated in the inset of Figure 6. Fittings in the plots of PL intensity vs $\mathrm{T}^{-1}$ yield the activation/binding energies $\left(E_{\mathrm{a}}\right)$ of 5 and $13 \mathrm{meV}$ for $\# 1 \mathrm{a}$ and \#1b, respectively. The binding energies of \#1a and \#1b are further confirmed by their peak locations at 5.4 and 12.6 $\mathrm{meV}$, respectively, below the band gap energy of $1.055 \mathrm{eV}$.

Features in groups \#2-\#7 are similar to those reported in previous PL observations of CuInSe 2 crystals. ${ }^{34-36}$ Both \#2 and
\#3 have one sharp peak at the leading edge, followed by a broad overlapping. The separations of \#1c, \#2a, and \#3a are 29.2$29.5 \mathrm{meV}$, close to the reported LO phonon mode of $28.9 \mathrm{meV}$ $\left(233 \mathrm{~cm}^{-1}\right)$ determined by Raman scattering spectroscopy. ${ }^{37} \mathrm{In}$ view of the relative intensities of \#1c, \#2a, and \#3a with a gradual decrease in intensity and a comparable phonon-energy separation, these three peaks should belong to a series of vibrational progression. Therefore, \#2a and \#3a are assigned to the $1 \mathrm{LO}$ and $2 \mathrm{LO}$ replicas of the strong \#1c signal of boundexciton emission.

Other transitions of groups \#2 and \#3 in Figure 6 are ascribed to the emissions related to different defect centers. The \#2b $(0.9977 \mathrm{eV})$ and \#3b $(0.9658 \mathrm{eV})$ peaks correspond to free-tobound transitions with the bound states lying at 57 and $89 \mathrm{meV}$, respectively, below the energy band gap of $1.055 \mathrm{eV}$. Theoretical prediction for the energies of defect formations can be used as a guideline to identify probable defect centers responsible for the two defect levels. ${ }^{38}$ According to the theoretical estimation of Wasim, ${ }^{38}$ the formation energies of the two lowest intrinsic defects are $1.4 \mathrm{eV}$ for $\mathrm{In}_{\mathrm{Cu}}$ (indium on copper antisite) and 1.5 $\mathrm{eV}$ for $\mathrm{Cu}_{\text {In }}$ (copper on indium antisite). However, an ab initio self-consistent calculation of the electronic structures of $\mathrm{CuInSe}_{2}$ chalcogenide by Zhang et al. ${ }^{39}$ showed that it is easier to form a $\mathrm{Cu}$ vacancy $\left(\mathrm{V}_{\mathrm{Cu}}\right)$ than the antisites of $\mathrm{In}_{\mathrm{Cu}}$ and $\mathrm{Cu}_{\mathrm{In}}$. The calculated formation energies of $\mathrm{V}_{\mathrm{Cu}}, \mathrm{In}_{\mathrm{Cu}}$, and $\mathrm{Cu}_{\text {In }}$ are 0.60 , 1.85 , and $1.54 \mathrm{eV}$, respectively. On the basis of the study of activation energies for the native point defects of $\mathrm{CuInSe}_{2}$ by Rincón et al., ${ }^{27}$ the observed acceptor level of \#2b with $E_{\mathrm{a}}=$ $57 \mathrm{meV}$ is likely due to the acceptor defects of $\mathrm{V}_{\mathrm{Cu}}, \mathrm{Se}_{\mathrm{In}}$ (selenium on indium antisite), or $\mathrm{Cu}_{\mathrm{Se}}$ (copper on selenium antisite). By taking into account both the favorably lower formation energy ${ }^{38,39}$ and the $E_{\mathrm{a}}=45 \pm 12 \mathrm{meV}$ calculated for acceptor levels, ${ }^{27} \# 2 \mathrm{~b}$ is assigned to the vacancy defect of $\mathrm{V}_{\mathrm{Cu}}$.

Peak \#3b, with $E_{\mathrm{a}}=89 \mathrm{meV}$, is located in the energy range of acceptor levels according to previous studies. ${ }^{27,35}$ The $E_{\mathrm{a}}=$ $83 \mathrm{meV}$ for $\mathrm{Cu}_{\mathrm{In}}$, calculated from the optical transitions observed in $\mathrm{Cu}$-rich $\mathrm{CuInSe}_{2}$ thin films, ${ }^{33}$ is close to the observed $E_{\mathrm{a}}=$ $89 \mathrm{meV}$ for \#3b. However, the defects of interstitial selenium $\left(\mathrm{Se}_{\mathrm{i}}\right)$ and $\mathrm{Cu}_{\text {In }}$ in $\mathrm{CuInSe} \mathrm{I}_{2}$ with their $E_{\mathrm{a}}=78 \pm 20 \mathrm{meV}$ calculated by Rincón et al. ${ }^{27}$ could also be responsible for peak \#3b. While others assigned the acceptor level of this energy range to $\mathrm{Cu}_{\mathrm{In}},{ }^{40} \mathrm{Kazmerski}$ et al. ${ }^{41}$ identified an acceptor level of $E_{\mathrm{a}} \sim 60 \mathrm{meV}$ to $\mathrm{Se}_{\mathrm{i}}$. Taking the formation energy into consideration, ${ }^{38}$ the defect of $\mathrm{Cu}_{\mathrm{In}}$ is easier to create than $\mathrm{Se}_{\mathrm{i}}$; therefore, \#3b is assigned to $\mathrm{Cu}_{\text {In }}$ in this work. The $\mathrm{Cu}_{\text {In }}$ defect has also been reported to exist in p-type $\mathrm{CuInSe}_{2}$ films. ${ }^{34-36,40}$

Weak and broad peak \#4 centered at $0.9366 \mathrm{eV}$ is assigned to the LO phonon replica of \#3b based on the relative intensities of these two peaks and their separation of $29.2 \mathrm{meV}$, comparable to the LO phonon energy. It has been found that the PL resulting from donor-acceptor pair (DAP) transitions ${ }^{34}$ appears at $\sim 0.9$ eV. Peak \#5 at $0.8983 \mathrm{eV}$, close to the DAP transitions, is identified as another free-to-bound transition involving a deep level of $E_{\mathrm{a}}=156.7 \mathrm{meV}$. In this work, the cation/anion ratio for the $\mathrm{CuInSe}_{2} \mathrm{NRs}$ is determined to be 0.95 from the EDS analysis. With this cation/anion ratio, the $\mathrm{Se}_{\mathrm{i}}$ defect with $E_{\mathrm{a}}=$ $184 \pm 45 \mathrm{meV}$ calculated by Rincón et al. ${ }^{27}$ can account for the observed acceptor level of peak \#5 with $E_{\mathrm{a}}=156.7 \mathrm{meV}$. Peak \#6 at $0.8686 \mathrm{eV}$ is $29.7 \mathrm{meV}$ from peak \#5. Of similar separation, peak \#7 at $0.8412 \mathrm{eV}$ is $27.4 \mathrm{meV}$ from peak \#6. As discussed earlier about the phonon replicas, \#6 and \#7 are assigned to the $1 \mathrm{LO}$ and $2 \mathrm{LO}$ of \#5. The LO modes of 27.4$29.7 \mathrm{meV}\left(221-240 \mathrm{~cm}^{-1}\right)$ phonon energy in the present experiment is in good agreement with the phonon frequency of 
TABLE 1: Observed PL Transitions of CuInSe $\mathrm{CNRs}_{2}$ with Their Peak Energies and Spectroscopic Assignments

\begin{tabular}{ccl}
\hline peak & peak energy $(\mathrm{eV})$ & \multicolumn{1}{c}{ spectroscopic assignment } \\
\hline$\# 1 \mathrm{a}$ & 1.0496 & free exciton emission \\
\#1b & 1.0424 & free exciton emission \\
\#1c & 1.0312 & bound exciton emission \\
$\# 1 \mathrm{~d}$ & 1.0245 & bound exciton emission \\
$\# 2 \mathrm{a}$ & 1.0020 & phonon replica $(1 \mathrm{LO})$ of \#1c \\
$\#$ 2b & 0.9977 & copper vacancy $\left(\mathrm{V}_{\mathrm{Cu}}\right)$ \\
$\# 3 \mathrm{a}$ & 0.9725 & phonon replica $(2 \mathrm{LO})$ of \#1c \\
$\# 3 \mathrm{~b}$ & 0.9658 & copper on indium antisites $\left(\mathrm{Cu}_{\mathrm{In}}\right)$ \\
$\# 4$ & 0.9366 & phonon replica $(1 \mathrm{LO})$ of \#3b \\
$\# 5$ & 0.8983 & interstitial selenium $\left(\mathrm{Se} \mathrm{e}_{\mathrm{i}}\right)$ \\
$\# 6$ & 0.8686 & phonon replica $(1 \mathrm{LO})$ of \#5 \\
$\# 7$ & 0.8412 & phonon replica $(2 \mathrm{LO})$ of \#5
\end{tabular}

$233 \mathrm{~cm}^{-1}$ observed by Raman spectroscopy. ${ }^{37}$ The observed PL transitions with their peak energies and spectroscopic assignments are tabulated in Table 1.

\section{Conclusions}

Single-crystalline CuInSe ${ }_{2} \mathrm{NRs}$ have been successfully synthesized in a soft solvothermal reaction with ethylenediamine as the reaction solvent. The growth of $\mathrm{CuInSe}_{2} \mathrm{NRs}$ stems from the chelated-complex formation of $\left[\mathrm{Cu}\left(\mathrm{H}_{2} \mathrm{NCH}_{2} \mathrm{CH}_{2} \mathrm{NH}_{2}\right)_{2}\right]^{+}$, which serves as a molecular template to combine with $\mathrm{InSe}_{2}{ }^{-}$ for the growth of one-dimensional nanostructures. XRD and electron microscopic measurements of $\mathrm{CuInSe}_{2} \mathrm{NRs}$ have shown a single-crystalline structure for the chalcopyrite crystals. The NIR absorption spectrum, room-temperature Raman scattering, and cryogenic PL from the $\mathrm{CuInSe}_{2} \mathrm{NRs}$ have further been examined to optically characterize the single-crystalline onedimensional chalcopyrite nanorods.

Acknowledgment. We acknowledge the electron microscopic measurements of SEM, TEM, and HRTEM conducted at the Center for Nano Science and Technology at National Taiwan University, the Instrumentation Center of National Taiwan University, and the Instrumentation Center of National Tsing-Hua University, sponsored by the National Science Council of ROC. This work is supported by the National Science Council of ROC (Grant Nos. 93-2113-M-002-027 and 94-2627M-002-003).

\section{References and Notes}

(1) Chapin, D. M.; Fuller, C. S.; Pearson, G. L. J. Appl. Physiol. 1954, 25, 676 .

(2) Green, M. A. High Efficiency Silicon Solar Cells; Trans Tech Publications: Switzerland, 1987.

(3) Chung, B. C.; Virshup, G. F.; Hikido, S.; Kaminar, N. R. Appl. Phys. Lett. 1989, 55, 1741.

(4) Bertness, K. A.; Ristow, M. L.; Hamaker, H. C. 20th IEEE Photovoltaic Specialists Conference Record; IEEE: New York, 1988; p 769.
(5) Antypas, G. A.; Moon, R. L. J. Electrochem. Soc. 1974, 120, 1574.

(6) Nadenau, V.; Braunger, D.; Hariskos, D.; Kaiser, M.; Koble, C.; Ruckh, M.; Schaffer, R.; Schmid, D.; Walter, T.; Zwergart, S.; Schock, H. W. Prog. Photogr. Res. Appl. 1995, 3, 363.

(7) Stolt, L.; Bodegard, M.; Kessler, J.; Ruckh, M.; Velthaus, K. O.; Schock, H. W. Proceedings of the 11th European Photovoltaic Solar Energy Conference; Monteux, Harwood Academic: Chur, Switzerland; 1993; p 20.

(8) Niki, S.; Fons, P. J.; Yamada, A.; Hellman, O.; Kurafuji, T.; Chichibu, S.; Nakanishi, H. Appl. Phys. Lett. 1996, 69, 647.

(9) Tiwari, A. N.; Blunier, S.; Filmoser, M.; Zogg, H.; Schmid, D.; Schock, H. W. Appl. Phys. Lett. 1994, 65, 3347.

(10) Takenoshita, H. Sol. Cells 1986, 16, 65

(11) Igarashi, O. J. Cryst. Growth 1993, 130, 343.

(12) Sagnes, B.; Salesse, A.; Artaud, M. C.; Duchemin, S.; Bougnot, J.; Bougnot, G. J. Cryst. Growth 1992, 124, 620.

(13) Malik, M. A.; O'Brien, P.; Revaprasadu, N. Adv. Mater. 1999, 11, 1441.

(14) Li, B.; Xie, Y.; Huang, J.; Qian, Y. Adv. Mater. 1999, 11, 1456.

(15) Yang, Y. H.; Wu, S. J.; Chiu, H. S.; Lin, P. I.; Chen, Y.-T. J. Phys. Chem. B 2004, 108, 846.

(16) Venugopal, R.; Lin, P.-I.; Liu, C.-C.; Chen, Y.-T. J. Am. Chem. Soc. 2005, 127, 11262

(17) Venugopal, R.; Lin, P.-I.; Chen, Y.-T. J. Phys. Chem. B 2006, 110, 11691

(18) Glinka, Y. D.; Lin, S. H.; Chen, Y.-T. Phys. Rev. B 2002, 66, 035404 and references therein.

(19) Jiang, T.; Ozin, G. A.; Bedard, R. L. Adv. Mater. 1994, 6, 860.

(20) Wang, W.; Geng, Y.; Qian, Y.; Ji, M.; Liu, X. Adv. Mater. 1998, $10,1479$.

(21) Li, Y. D.; Liao, H. W.; Ding, Y.; Qian, Y. T.; Yang, L.; Zhou, G. E. Chem. Mater. 1998, 10, 2301.

(22) Alcamí, M.; Luna, A.; Mó, O.; Yáñez, M.; Tortajada, J. J. Phys Chem. A 2004, 108, 8367.

(23) Morris, R. E.; Weigel, S. J. Chem. Soc. Rev. 1997, 26, 309.

(24) Trindade, T.; O'Brien, P.; Zhang, X. Chem. Mater. 1997, 9, 523.

(25) Mooney, G. D.; Hermann, A. M.; Tuttle, J. R.; Albin, D. S.; Noufi, R. Sol. Cells 1991, 30, 69.

(26) Kavcar, N. Sol. Energy Mater. Sol. Cells 1998, 52, 183.

(27) Rincón, C.; Márquez, R. J. Phys. Chem. Solids 1999, 60, 1865.

(28) Matsushita, H.; Endo, S.; Irie, T. Jpn. J. Appl. Phys. 1992, 31, 18.

(29) Roy, S.; Guha, P.; Kundu, S. N.; Hanzawa, H.; Chaudhuri, S.; Pal, A. K. Mater. Chem. Phys. 2002, 73, 24.

(30) Neumann, H. Sol. Cells 1986, 16, 317.

(31) Shay, J. L. Ternary Chalcopyrite Semiconductors: Growth, Electronic Properties, \& Applications; Shay, J. L., Wernick, J. H., Eds. Pergamon Press: Oxford, 1975; Chapter 4, p 110.

(32) Yakushev, M. V.; Feofanov, Y.; Martin, R. W.; Tomlinson, R. D.; Mudryi, A. V. J. Phys. Chem. Solids 2003, 64, 2011.

(33) Yakushev, M. V.; Mudryi, A. V.; Tomlinson, R. D. Appl. Phys Lett. 2003, 82, 3233

(34) Niki, S.; Makita, Y.; Yamada, A.; Obara, A.; Misawa, S.; Igarashi, O.; Aoki, K.; Katsuwada, N. Jpn. J. Appl. Phys. 1994, 33, L500.

(35) Zott, S.; Leo, K.; Ruckh, M.; Schock, H. W. J. Appl. Phys. 1997, 82,356 .

(36) Yu, P. W. J. Appl. Phys. 1976, 47, 677.

(37) Tanino, H.; Maeda, T.; Fujikake, H.; Nakanishi, H.; Endo, S.; Irie, T. Phys. Rev. B 1992, 45, 13323.

(38) Wasim, S. M. Sol. Cells 1986, 16, 289.

(39) Zhang, S. B.; Wei, Su-Huai; Zunger, A. Phys. Rev. Lett. 1997, 78, 4059.

(40) Rockett, A.; Birkmire, R. W. J. Appl. Phys. 1991, 70, R81.

(41) Kazmerski, L. L. Jpn. J. Appl. Phys. Suppl. 1993, 32/33, 25. 